\title{
Effect of an Educational Intervention on the Knowledge of Young Researchers on COVID-19
}

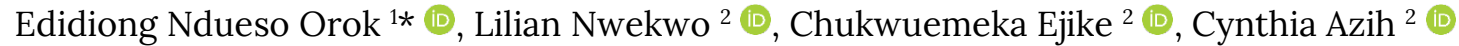

\author{
${ }^{1}$ Department of Clinical Pharmacy and Pharmacy Administration, University of Ibadan, Ibadan, NIGERIA \\ ${ }^{2}$ Faculty of Pharmacy, University of Nigeria, Nsukka, NIGERIA \\ *Corresponding Author: pharmorok@gmail.com
}

Citation: Orok EN, Nwekwo L, Ejike C, Azih C. Effect of an Educational Intervention on the Knowledge of Young Researchers on COVID19. Journal of Contemporary Studies in Epidemiology and Public Health. 2021;2(1):ep21004. https://doi.org/10.30935/jconseph/11026

\begin{abstract}
Introduction: COVID-19 is a global pandemic that was discovered in Wuhan, China. Since its discovery, health measures have been put in place to help curb its spread but compliance with these measures has not been optimum due to inadequate education. Proper education on COVID-19 is important as it is associated with improvement in compliance to health control measures as well as knowledge of the disease.
\end{abstract}

Aim: This study was carried out to evaluate the impact of an educational intervention on the knowledge of young researchers on COVID-19.

Methods: This study was a cross-sectional, pre- and post-interventional study carried out among researchers that were part of a WhatsApp group between August and September 2020. The knowledge of the participants was evaluated first after which an educational intervention was provided via an online WhatsApp lecture on COVID-19. The participants were examined post-intervention using the same knowledge questions used before the training.

Results: A total of 46 participants consented to participate with mean age of 23.78 (SD:3.705 years). More than 54\% showed poor knowledge at pre-intervention. There was a significant improvement in knowledge at postintervention as more than $54 \%$ showed excellent knowledge. There was a statistically significant difference in mean knowledge scores of the participants between pre-intervention and post-intervention, $\mathrm{p}<0.001$.

Conclusion: Educational intervention has a significant impact on the knowledge of participants as shown in this study. There was an improvement in the knowledge of the study participants at post-intervention. There is need for regular online educational programs that can improve knowledge on COVID-19.

Keywords: educational intervention, Nigeria, online training, young researchers, knowledge on COVID-19

Received: 3 Dec. 2020 • Accepted: 25 Jan. 2021

\section{INTRODUCTION}

Corona virus disease 2019 (COVID-19) was detected in Wuhan, China precisely in December 2019 and this disease has been reported to have a higher vulnerability in older patients $[1,2]$. The novel disease has affected many countries across the globe and this has affected different sectors of their economy [3]. The novel type of corona virus called SARS-CoV-2 was identified as the cause of the pneumonia of unknown aetiology which was the major complain reported by almost all affected individuals [4]. As of 30th January, 2020, it was declared a Public Health Emergency of International Concern [5] and the first case in subSaharan Africa was reported in Nigeria in February 2020 [6]. The COVID-19 outbreak was declared a pandemic by the Director-General of the World Health Organisation (WHO) on 11th March, 2020 [7].

Public health measures has been put in place to curb the further spread of the virus and this has been documented in standardised guidelines proposed by the WHO and NCDC in Nigeria [8,9]. As regards tackling this public health disaster, adequate knowledge is important as this has been reported to bring about positive health outcomes made possible through education [10,11]. Education and awareness are important factors that can improve adherence to public health control measures of major outbreaks including COVID-19 [12]. This is because education enlightens an individual and improves the perceived knowledge of an issue. Knowledge of the public is assumed to have a great outcome on their ability to adhere strictly to control measures and also take up new measures when necessary but knowledge gaps contribute greatly to the poor adherence to control measures $[13,14]$.

To see to it that the current crisis is properly handled and that future outbreaks are prevented, the need to provide educational interventions tailored to improve the knowledge of the public as regards the COVID-19 pandemic can never be over-emphasized [10].

Studies to evaluate the knowledge of the population in different areas have produced mixed results which includes overall good knowledge [15,16] and poor knowledge [17] reported among the participants. Each of these studies stressed the need for educational 
interventions to help improve participant knowledge. However, limited studies have been carried out to evaluate the effect of education on the knowledge of participants on COVID-19. This study was carried out to evaluate the impact of an educational intervention on the knowledge of young researchers on COVID-19. This study reviewed the current knowledge of young researchers and also assessed their knowledge after an educational intervention.

\section{MATERIALS AND METHODS}

\section{Ethical Considerations}

The study protocol was approved by the University of Ibadan/University College Hospital Ethics Committee, with approval number UI/EC/20/0065. The study was conducted in accordance with the ethical standards as laid down in the 1964 Declaration of Helsinki and its later amendments [18].

\section{Study Design}

This study was a prospective cross-sectional and interventional study.

\section{Study Population}

This study was carried out among young researchers that comprised of students of the medical sciences and pharmacists.

\section{Sample Size Determination and Sampling Technique}

Convenience sampling technique was employed in the sampling of the study participants for this study. The participants were members of a researcher's group and the consenting participants were enrolled in the study. A total of 100 members were sampled to be part of the study as that was the total number of people in the group. The final sample size for the study was determined using the number of participants that consented to participate in the study. The total number of participants that consented to participate in this study was 46 representing approximately $46 \%$ response rate.

\section{Data Collection Instrument}

The instrument that was used to collect data in this study was a pretested 22-item online questionnaire. The questionnaire comprised of demographics and the knowledge assessment sections. The demographics section consisted of 6 items while sixteen questions were used to assess the participants' knowledge. The demographics assessed in this study were age, additional qualification, gender, course of study of the students, and occupation. The knowledge assessment questions covered; transmission of COVID-19, diagnosis of COVID-19, incubation period of COVID-19, prevalence of COVID-19 and preventive measures for COVID-19. The questions asked were true or false and multiple-choice questions. The knowledge questions were coined based on the World Health Organisation (WHO) and Nigerian Centre for Disease Control (NCDC) guidelines on COVID-19 $[8,9]$.

\section{Validation of Instrument}

The questionnaire used in this study was validated using face validity among lecturers and experts in the field of study. The questionnaire was also pre-tested among 5 researchers that were not included in the final analysis and the Cronbach alpha value obtained from the pre-test was 0.71 .

\section{Protocol}

All the participants were informed about the study objectives and the study synopsis after which a statement of informed consent was presented to them. The participants that clicked yes had access to the demographics and knowledge questions section of the questionnaire while clicking no marked the end of the survey by the participant. The participants' baseline knowledge on COVID-19 was assessed. This was followed by an educational intervention provided via an online WhatsApp lecture. The participants' knowledge was assessed again after the training. The educational training was designed based on NCDC COVID-19 public health guidelines [9] and it covered; full meaning and origin of COVID-19; mode of transmission of COVID19; diagnosis of COVID-19; population at risk of COVID-19; preventive measures against COVID-19; common symptoms of COVID-19; difference between quarantine and self-isolation.

\section{Data Analysis}

Age of the participants was expressed as mean and standard deviation. Gender, additional qualifications and other categorical variables was expressed as percentages and proportions. The knowledge of the participants was categorised into poor knowledge (< $50 \%$ knowledge score), intermediate (50-69\% knowledge score) and excellent knowledge ( $\geq 70 \%$ knowledge score). The difference in knowledge of the participants before and after the educational intervention was analysed using the paired sample t-test. Association between participants' demographics and knowledge of the participants was analysed using the Pearson's Chi-square test. All analysis was carried out with the use of Statistical Package for Social Sciences, SPSS, for windows version 25 . Statistical differences were set at $\mathrm{p}<0.05$.

\section{RESULTS}

\section{Demographics}

A total of 46 participants consented to participate in the study. Eighteen (39.1\%) were male and 28 (60.9\%) were female (Table 1). More than $80 \%$ (37) were students while 9 (19.6\%) were pharmacists (Table 1). The mean age of the study participants was $23.78 \pm 3.705$ years (Range: $18-42$ years) (Table 1 ).

Thirty students studied Pharmacy, two studied Biochemistry and health education while one studied Medicine and Surgery, Nursing science and Microbiology respectively (Table 1).

\section{Knowledge of Study Participants on COVID-19}

A total of 16 questions on COVID-19 were asked the participants. At pre-intervention, majority of the participants correctly reported that; the meaning of COVID-19 is coronavirus disease discovered in 2019 (41; 89.1\%), it is not easy to tell when someone has COVID-19 since not everyone has symptoms (40; 87.0\%) and the incubation period for COVID-19 is 2 days to 2 weeks (39; 84.8\%) (Table 2). A total of seven statements were answered correctly by a small percentage of the participants and they were; novel coronavirus is not the same as coronavirus disease $(6 ; 13.0 \%)$; males are the mostly affected gender by COVID-19 (15.2\%; 7); people with COVID-19 but without symptoms can transmit the virus to others $(10 ; 21.7 \%)$; there is no cure yet for COVID-19 (14; 30.4\%); washing of hands for 20 seconds, use of at least $60 \%$ alcohol based sanitizer and use of facemasks are measures that can protect one from COVID-19 (21; 45.7\%); COVID-19 cannot be 
Table 1. Demographics of study participants

\begin{tabular}{|c|c|c|c|}
\hline \multicolumn{2}{|c|}{ Demographics } & Number & Percent \\
\hline \multirow{2}{*}{ Gender } & Male & 18 & 39.1 \\
\hline & Female & 28 & 60.9 \\
\hline \multirow{2}{*}{ Occupation } & Students & 37 & 80.4 \\
\hline & Pharmacists & 9 & 19.6 \\
\hline \multirow[b]{2}{*}{ Additional Qualification } & None & 44 & 95.6 \\
\hline & MSc. & 1 & 2.2 \\
\hline Mean age & \multicolumn{3}{|c|}{$23.78 \pm 3.705$ years, range $18-42$ years } \\
\hline \multirow{5}{*}{ Course of study of the student participants } & Pharmacy & 30 & 81.1 \\
\hline & Biochemistry & 2 & 5.4 \\
\hline & Health Education & 2 & 5.4 \\
\hline & Medicine and Surgery & 1 & 2.7 \\
\hline & Microbiology & 1 & 2.7 \\
\hline
\end{tabular}

Table 2. Performance of the participants to questions before the training

\begin{tabular}{|c|c|c|}
\hline $\mathbf{S} / \mathbf{N}$ & Statements & Correct (\%) \\
\hline 1 & Novel coronavirus is not the same as COVID-19 & $6(13)$ \\
\hline 2 & COVID-19 stands for Coronavirus disease discovered in 2019 & $41(89.1)$ \\
\hline 3 & The male gender is the most affected by COVID-19 & $7(15.2)$ \\
\hline 4 & The elderly and patients with underlying medical condition run a greater risk of being affected severely by COVID- 19 & $23(50)$ \\
\hline 5 & People with COVID-19 but without symptoms can still transmit the virus to others & $10(21.7)$ \\
\hline 6 & COVID-19 cannot be cured & 14(30.4) \\
\hline 7 & Droplets from the nose and mouth when coughing or breathing out are among the common ways of transmitting COVID-19 & $31(67.4)$ \\
\hline 8 & Cough, fever and difficulty in breathing are common symptoms of COVID-19 & $36(78.3)$ \\
\hline 9 & It is not easy to tell when someone has COVID-19 because not everyone has symptoms & $40(87)$ \\
\hline 10 & $\begin{array}{l}\text { Washing of hands with running water for at least } 20 \text { seconds, use of hand sanitizer with at least } 60 \% \text { alcohol and use of face } \\
\text { mask when in a public place are measures that can protect one from COVID- } 19\end{array}$ & $21(45.7)$ \\
\hline 11 & Incubation period for COVID-19 is 2 days to 2 weeks & $39(84.8)$ \\
\hline 12 & COVID-19 cannot be considered an airborne disease & $21(45.7)$ \\
\hline 13 & A temperature of 39 degrees Celsius is considered a risk when screening patients for COVID-19 & $37(80.4)$ \\
\hline 14 & Polymerase chain reaction test is the current recommended diagnostic test for COVID-19 & $28(60.9)$ \\
\hline 15 & Avoiding conversations and avoiding speaking on the phone are not social distancing measures & $23(50)$ \\
\hline 16 & $\begin{array}{l}\text { Self-isolation involves separating people who are ill from others while quarantine involves isolating people that have been } \\
\text { exposed to a disease to see if they will fall sick }\end{array}$ & 10(21.7) \\
\hline
\end{tabular}

Table 3. Association between demographics and knowledge of participants before the training

\begin{tabular}{|c|c|c|c|c|c|}
\hline \multirow{2}{*}{\multicolumn{2}{|c|}{ Demographics }} & \multicolumn{3}{|c|}{ Knowledge score of study participants } & \multirow{4}{*}{$\begin{array}{c}\mathbf{p}^{-v^{2}} \text { alue }^{\mathbf{a}} \\
0.426\end{array}$} \\
\hline & & \multirow{2}{*}{$\begin{array}{c}\text { Poor Knowledge }(<\mathbf{5 0} \%) \\
10\end{array}$} & \multirow{2}{*}{$\begin{array}{c}\text { Intermediate knowledge (50- } \\
69 \%)\end{array}$} & \multirow{2}{*}{$\begin{array}{c}\text { Excellent Knowledge }(\geq 70 \%) \\
1\end{array}$} & \\
\hline \multirow{2}{*}{ Gender } & Male & & & & \\
\hline & Female & 15 & 13 & 0 & \\
\hline \multirow{2}{*}{ Occupation } & Student & 21 & 16 & 1 & \multirow{2}{*}{0.116} \\
\hline & Pharmacist & 4 & 4 & 0 & \\
\hline \multirow{3}{*}{ Additional Qualification } & None & 24 & 20 & 0 & \multirow{3}{*}{$0.000^{*}$} \\
\hline & MSc. & 0 & 0 & 1 & \\
\hline & Ph.D. & 1 & 0 & 0 & \\
\hline
\end{tabular}

Key: ${ }^{\mathrm{a}}=$ Pearson Chi-square test. MSc. $=$ Master of Science degree. Ph.D. $=$ Doctor of Philosophy degree

* $=$ Statistically significant value $(\mathrm{p}<0.05)$

considered an airborne disease (21;45.7\%); self-isolation involves separating people who are ill from others while quarantine involves isolating people that have been exposed to a disease to see if they will fall sick (10; 21.7\%) (Table 2). Overall, a little above 54\% (25) of the participants scored less than $50 \%$ representing poor knowledge while 20 (43.5\%) participants scored between 50-69\% representing intermediate knowledge before the educational intervention (Figure 1). There was no association between gender $(\mathrm{p}=0.426)$, occupation $(\mathrm{p}=0.116)$ and knowledge of participants but there was a significant association between additional qualification and knowledge of the study participants $(\mathrm{p}<0.001)$ (Table 3). After the training, the participants showed an improvement in knowledge as $25(54.3 \%)$ scored $70 \%$ and above showing excellent knowledge while $45.7 \%$ (21) scored between 50-69\% representing intermediate knowledge on COVID-19 (Figure 1). The mean knowledge score of participants before the training was $9.33 \pm 2.098$ points (range: $4-16$ points) and $14.17 \pm 2.751$ points (range: 10-20 points) after the training (Table 4). There was a statistically 


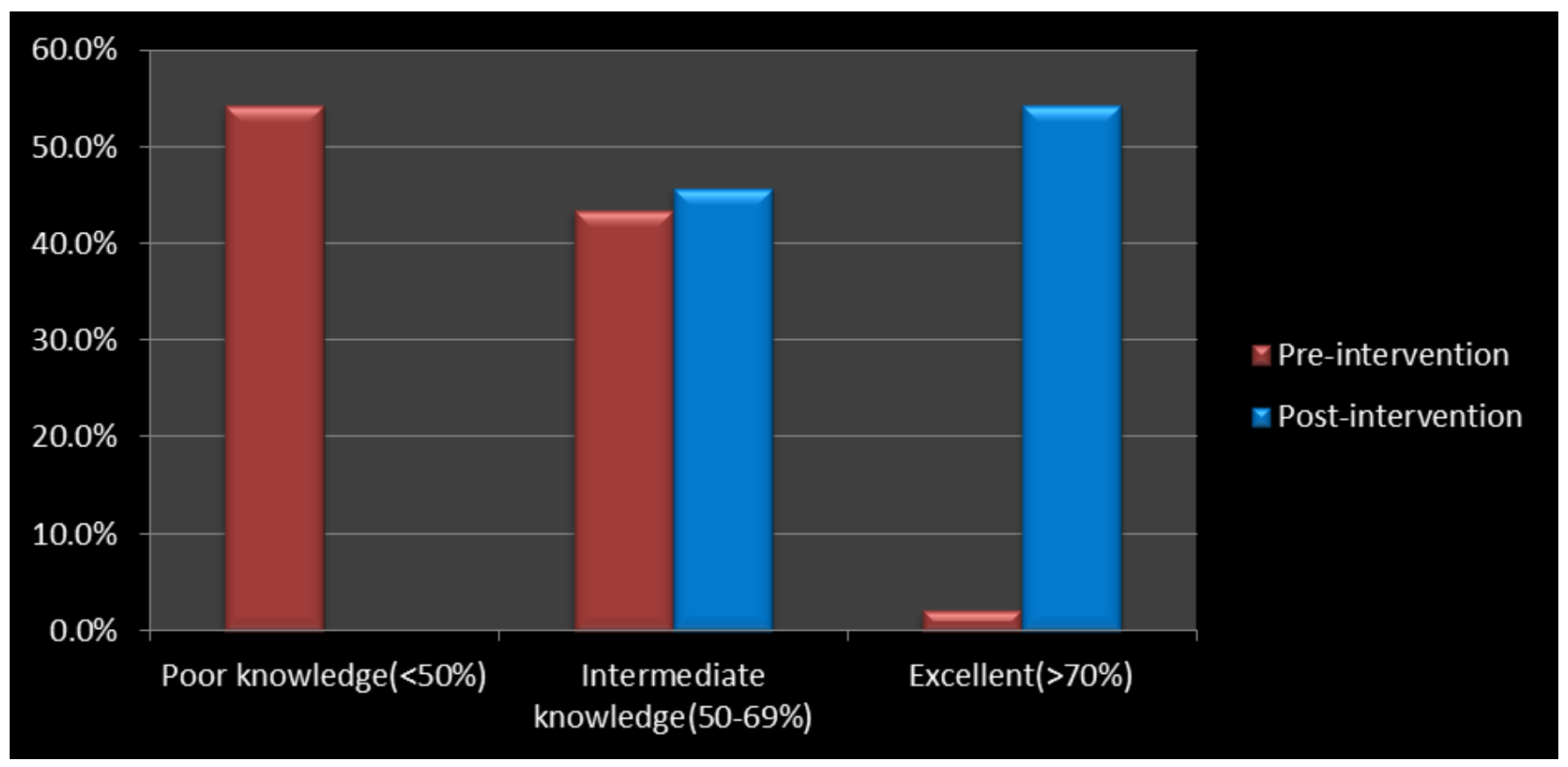

Figure 1. Overall knowledge of participants at pre- and post-intervention

Table 4. Effect of educational training on the knowledge of study participants

\begin{tabular}{|c|c|c|c|}
\hline \multirow{2}{*}{ Statements } & Before training & After training & \multirow{2}{*}{ p-value ${ }^{a}$} \\
\hline & Correct (\%) & Correct (\%) & \\
\hline Novel coronavirus is not the same as COVID-19 & 6(13) & $46(100)$ & $0.000^{*}$ \\
\hline COVID-19 stands for Coronavirus disease discovered in 2019 & $41(89.1)$ & $42(91.3)$ & 0.323 \\
\hline The male gender is the most affected by COVID-19 & $7(15.2)$ & $44(95.7)$ & $0.003^{*}$ \\
\hline $\begin{array}{l}\text { The elderly and patients with underlying medical condition run a greater risk of being affected severely by } \\
\text { COVID-19 }\end{array}$ & $23(50)$ & $33(71.7)$ & $0.001^{*}$ \\
\hline People with COVID-19 but without symptoms can still transmit the virus to others & $10(21.7)$ & $36(78.3)$ & $0.000^{*}$ \\
\hline There is no current treatment for COVID-19 & $14(30.4)$ & $41(89.1)$ & $0.000^{*}$ \\
\hline $\begin{array}{l}\text { Droplets from the nose and mouth when coughing or breathing out are among the common ways of } \\
\text { transmitting COVID-19 }\end{array}$ & $31(67.4)$ & $34(73.9)$ & 0.083 \\
\hline Cough, fever and difficulty in breathing are common symptoms of COVID-19 & $36(78.3)$ & $38(82.6)$ & 0.160 \\
\hline It is not easy to tell when someone has COVID-19 because not everyone has symptoms & $40(87)$ & $41(89.1)$ & 0.323 \\
\hline $\begin{array}{l}\text { Washing of hands with running water for at least } 20 \text { seconds, use of hand sanitizer with at least } 60 \% \text { alcohol } \\
\text { and use of face mask when in a public place are measures that can protect one from COVID-19 }\end{array}$ & $21(45.7)$ & 28(60.9) & $0.007^{*}$ \\
\hline Incubation period for COVID-19 is 2 days to 2 weeks & 39(84.8) & $40(87.0)$ & 0.243 \\
\hline COVID-19 cannot be considered an airborne disease & $21(45.7)$ & $34(73.9)$ & $0.000^{*}$ \\
\hline A temperature of 39 degrees Celsius is considered a risk when screening patients for COVID-19 & $37(80.4)$ & $38(82.6)$ & 0.323 \\
\hline Polymerase chain reaction test is the current recommended diagnostic test for COVID-19 & $28(60.9)$ & $37(80.4)$ & $0.002^{*}$ \\
\hline Avoiding conversations and avoiding speaking on the phone are not social distancing measures & $23(50)$ & $33(71.7)$ & $0.001^{*}$ \\
\hline $\begin{array}{l}\text { Self-isolation involves separating people who are ill from others while quarantine involves isolating people } \\
\text { that have been exposed to a disease to see if they will fall sick }\end{array}$ & $10(21.7)$ & $40(87.0)$ & $0.000^{*}$ \\
\hline Mean Knowledge scores & $9.33 \pm 2.098$ & $14.17 \pm 2.751$ & $0.000^{*}$ \\
\hline
\end{tabular}

Key: a = Paired sample t-test. * = Statistically significant value $(\mathrm{p}<0.05)$

significant difference in the mean knowledge scores of the participants between pre-intervention and post-intervention, $\mathrm{p}<0.001$ (Table 4).

\section{DISCUSSION}

The purpose of this study was to evaluate the effect of an educational intervention on the knowledge of young researchers on
COVID-19. The results of this study showed that the online educational intervention had a significant effect as there was a significant increase in knowledge scores at post-intervention as compared to preintervention.

In this study, majority of the participants were females which is similar to what is obtainable in other studies $[15,17]$. This could be probably due to the higher proportion of females compared to males in 
those countries. Majority of the participants in this study had excellent knowledge on the incubation period of COVID-19 and that there is no treatment yet for COVID-19 which is similar to what was documented by Srichan et al. [17], Zegara et al. [19] and Ferdous et al. [20].

A greater percentage of the pharmacists showed at least intermediate knowledge on COVID-19 compared to students. This could be related to the fact that the participants, aside from students, were pharmacists who have access to knowledge on COVID-19 more regularly. This is confirmed in other studies where it was documented that occupation is associated with knowledge of COVID-19 [17,21]. However, gender and occupation were not associated with knowledge in the study participants at pre-intervention which is dissimilar to a study by Zhong et al. [15]. This could be because of the small sample size used in this study compared to a larger sample size used in other studies.

This study showed overall poor knowledge on COVID-19 by the participants at pre-intervention. This is different to what was obtained from other studies $[15,16]$. However, a study by Srichan et al. showed similar results [17]. This could possibly be due to over confidence in the participants and this shows the importance of regular health education programs on COVID-19.

There was a significant improvement in knowledge after the educational intervention which shows the need and importance of regular educational programs on COVID-19 highlighted in several studies $[15,17,21]$. The onset of COVID-19 has brought about the drifting and increased need for online education as reported in several studies [22-24]. The educational intervention was done online without any face-to-face contact which is beneficial to reduce the risk of spread of COVID-19 that can be possible through contact. Online health education has also been documented to be associated with improved knowledge when used among health professionals $[25,26]$. The result of this study goes further to reaffirm this as there was a significant improvement in knowledge of the participants. The study limitations include that the participants were all from the medical field and thus the results cannot be generalised to participants in other fields. Secondly, the study was done using a convenience sample which comprised of a relatively small sample size which will limit the generalizability of the results obtained.

More studies should be done to explore the effect of educational intervention on knowledge of a larger number of participants who are not in the medical field on COVID-19.

\section{CONCLUSIONS}

Proper health education through online lectures can have an impact on the knowledge of participants as shown in this study. There was a significant improvement in the knowledge of the study participants at post-intervention compared to pre-intervention as majority of the participants showed intermediate to excellent knowledge postintervention compared to poor to intermediate knowledge at preintervention. There is a need for regular educational programs that can aid to improve knowledge on COVID-19 which will improve adherence to preventive control measures against COVID-19 and help the populace eventually beat the pandemic.

Author contributions: All authors were involved in concept, design, collection of data, interpretation, writing, and critically revising the article. All authors approve final version of the article.
Funding: The authors received no financial support for the research and/or authorship of this article.

Declaration of in terest: Authors declare no competing interest.

Acknowledgements: The authors wish to thank all members of the young researchers group that participated in this study.

Data availability: Data generated or analysed during this study are available from the authors on request.

\section{REFERENCES}

1. Huang C, Wang Y, Li X, et al. Clinical features of patients infected with 2019 novel coronavirus in Wuhan, China. Lancet. 2020; 395:497-06. (doi: 10.1016/S0140-6736(20)30183-5).

2. Guan W, Ni Z, Hu Y, et al. Clinical Characteristics of Coronavirus Disease 2019 in China. N Engl J Med. 2020; 382:1708-20. (doi: 10.1056/NEJMoa2002032).

3. Pak A, Adegboye OA, Adekunle AI, Rahman KM, McBryde E. Economic Consequences of the COVID-19 Outbreak: The Need for Epidemic Preparedness.. Front. Public Health. 2020; 8:241. (doi: 10.3389/fpubh.2020.00241).

4. Lu H, Stratton C, Tang Y. Outbreak of pneumonia of unknown etiology in Wuhan, China: The mystery and the miracle. J. Med. Virol. 2020; 92:401-02. (doi: 10.1002/jmv.25678).

5. World Health Organization. Emergency Committee regarding the outbreak of novel coronavirus (2019-nCoV) (2020). Available at: https://www.who.int/news/item/30-01-2020-statement-on-thesecond-meeting-of-the-international-health-regulations--eme....

6. Coronavirus: Nigeria confirms first case in sub-Saharan Africa. Available at: https://www.bbc.com/news/world-africa-51671834

7. World Health Organization. Director-General's Opening Remarks at the Media Briefing on COVID-19-11 March 2020 (2020). Available at: https://www.who.int/dg/speeches/detail/whodirector-general-s-opening-remarks-at-the-media-briefing-oncovid-19---11-....

8. World Health Organisation. Advice for the public (2020). Available at: https://www.who.int/emergencies/diseases/novelcoronavirus-2019/advice-for-public

9. Nigerian Center for Disease Control. Public health advisory on COVID- 19: How to protect yourself (2020). Available at: https://covid19.ncdc.gov.ng/advisory/how-to-protect-yourself

10. Maslen S, Hayes J. Preventing black swans: Incident reporting systems as collective knowledge management. J Risk Res. 2016; 19(10):1246-60. (doi: 10.1080/13669877.2015.1057204). 
11. Hoffmann R, Lutz SU. The health knowledge mechanism: evidence on the link between education and health lifestyle in the Philippines. Eur J Health Econ. 2019; 20:27-43. (doi: 10.1007/s10198-017-0950-2).

12. Roma P, Monaro M, Muzi L, et al. How to Improve Compliance with Protective Health Measures during the COVID-19 Outbreak: Testing a Moderated Mediation Model and Machine Learning Algorithms. Int. J. Environ. Res. Public Health. 2020; 17:7252. (doi: 10.3390/ijerph17197252).

13. Dauda-Goni M, Hasan H, Naing N, et al. Assessment of Knowledge, Attitude and Practice towards Prevention of Respiratory Tract Infections among Hajj and Umrah Pilgrims from Malaysia in 2018. Int J Environ Res Public Health. 2018; 16:4569. (doi: 10.3390/ijerph16224569).

14. Noé A, Ribeiro R, Anselmo R, et al. Knowledge, attitudes, and practices regarding tuberculosis care among health workers in Southern Mozambique. BMC pul med. 2017; 17:2. (doi: 10.1186/s12890-016-0344-8).

15. Zhong B, Luo W, Li H, et al. Knowledge, attitudes, and practices towards COVID-19 among Chinese residents during the rapid rise period of the COVID-19 outbreak: a quick online cross-sectional survey. Int. J. Biol. Sci. 2020; 16:1745-52. (doi: 10.7150/ijbs.45221).

16. Saqlain M, Munir M, Rehman S, et al. Knowledge, attitude, practice, and perceived barriers among healthcare workers regarding COVID- 19: A cross-sectional survey from Pakistan. J. Hosp. Infect. 2020; 105:419-23. (doi: 10.1016/j.jhin.2020.05.007).

17. Srichan P, Apidechkul T, Tamornpark R, et al. Knowledge, Attitude and Preparedness to Respond to the 2019 Novel Coronavirus (COVID-19) Among the Bordered Population of Northern Thailand in the Early Period of the Outbreak. A CrossSectional Study. WHO South-East Asia J Public Health. 2020; 9:118-25. (doi: 10.2139/ssrn.3546046).

18. General Assembly of the World Medical Association. World Medical Association Declaration of Helsinki: ethical principles for medical research involving human subjects. J Am Col Dent.2014; 81.
19. Zegarra-Valdivia J, Chino Vilca B, Ames-Guerrero R. Knowledge, perception, and attitudes in Regard to COVID-19 Pandemic in Peruvian Population. PsyArXiv. 2020; 13:34-46. (doi: 10.31234/osf.io/kr9ya).

20. Ferdous MZ, Islam MS, Sikder MT, et al. Knowledge, attitude, and practice regarding COVID-19 outbreak in Bangladesh: An onlinebased cross-sectional study. PLoS ONE. 2020; 15:239254. (doi: 10.1371/journal.pone.0239254).

21. Ngwewondo A, Nkengazong L, Ambe L, et al. Knowledge, attitudes, practices of/towards COVID 19 preventive measures and symptoms: A cross-sectional study during the exponential rise of the outbreak in Cameroon. PLoS Negl Trop. Dis. 2020; 14:8700. (doi: 10.1371/journal.pntd.0008700).

22. Orok E, David S, Olajide T, Sulaiman A, Oyewole E. Effect of COVID-19 on the Mental Health and Social Activities of Healthcare Students in Southwestern Nigeria. Eur J Med and Educ Tech. 2020; 13:2015. (doi: 10.30935/ejmets/8569).

23. Carrillo C, Flores M. COVID-19, and teacher education: a literature review of online teaching and learning practices. Eur. J. Teach. Educ. 2020; 43:466-87. (doi: 10.1080/02619768.2020.1821184).

24. Adedoyin O, Soykan E. Covid-19 pandemic, and online learning: the challenges and opportunities. Interact. Learn. Environ. 2020; 20:1-13. (doi: 10.1080/10494820.2020.1813180).

25. Kyaw B, Saxena N, Posadzki P, et al. Virtual Reality for Health Professions Education: Systematic Review and Meta-Analysis by the Digital. Health Education Collaboration J Med Internet Res. 2019; 21:12959. (doi: 10.2196/12959).

26. Showande SJ, Orok EN. Impact of pharmacists' training on oral anticoagulant counseling: A randomized controlled trial. Patient Educ. Couns. 2020; 104(5): 1253-59 (doi: 10.1016/j.pec.2020.09.018). 